\title{
Assessment of Akodon cursor (Rodentia, Sigmodontinae) as permissive host to Schistosoma mansoni infection: morphology of adult worms
}

\author{
José Roberto Machado-Silva ${ }^{1,4^{*}}$, Renata Heisler Neves², Rosângela Rodrigues-Silva², \\ Regina Maria Figueiredo de Oliveira ${ }^{1}$ and Arnaldo Maldonado Júnior ${ }^{3}$
}

\begin{abstract}
${ }^{1}$ Laboratório Romero Lascasas Porto, Departamento de Microbiologia, Imunologia e Parasitologia, Faculdade de Ciências Médicas, UERJ, Av. Prof. Manoel de Abreu 444 - Vila Isabel, 20551-170, Rio de Janeiro, RJ, Brasil; ${ }^{2}$ Laboratório de Helmintos Parasitos de Vertebrados, Instituto Oswaldo Cruz, Rio de Janeiro, RJ, Brasil; ${ }^{3}$ Laboratório de Biologia e Parasitologia de Mamíferos Silvestres Reservatórios, Instituto Oswaldo Cruz, Rio de Janeiro, RJ, Brasil; ${ }^{4} \mathrm{CNPq}$ research fellow
\end{abstract}

\begin{abstract}
The natural infection with parasitic helminths is common in wild rodent populations. Once such interactions are better understood in the laboratory, it will be more feasible to extend the findings to infected hosts in nature. The flukes recovered from laboratory-infected Akodon cursor at 63 days post-infection were stained with hydrochloric carmine and individually mounted on glass slide as whole-mounts. Light and laser scanning confocal microscopy studies of adult male and female Schistosoma mansoni are reported. The parasites were examined morphologically and biometrically, which was obtained in a digital system for image analysis. Parameters used were: tegument thickness, digestive, excretory and reproductive systems. The overall conclusion of this experiment is that the morphological features of adult worm were similar to laboratory mice. It has been confirmed that the grass mouse is a permissive host to $S$. mansoni infection.
\end{abstract}

\section{Keywords}

Schistosoma mansoni, morphology, experimental infection, Acodon cursor, permissive host

\section{Introduction}

The analysis of the population dynamics of small rodent in Sumidouro (Rio de Janeiro, Brazil) indicated that the Brazilian grass mouse Akodon cursor (Winge, 1887) is one of the most abundant species (D'Andrea et al. 2007). On basis of biological, epidemiological, and ecological studies, the role of the water-rat Nectomys squamipes (Brants, 1827) in schistosomiasis transmission has been reported (D'Andrea et al. 2000). The studies of helminth fauna of natural wild hosts have in Brazil a long tradition (Amato 1976, Gomes and Vicente 1984, Maldonado et al. 2006, Souza et al. 2008). Besides its ecological importance, natural infection with parasitic helminths is common in A. cursor. Both nematode (Gomes et al. 2003) and schistosomiasis mansoni infections have been reported (Rodrigues-Silva et al. 1992).

For this reason, some species of wild rodents have been introduced for captive conditions and were employed as nat- ural-hosts animal models for schistosomiasis studies (Machado e Silva et al. 1991, Souza et al. 1992, Maldonado Jr. et al. 1994, Lenzi et al. 1995, Ribeiro et al. 1998).

Much of the interest in describing and modeling the population dynamics of helminths has concerned parasite fecundity in the definitive host (Toledo et al. 2006). However, morphological characteristics of adult worms demonstrate that phenotypic plasticity is an important means through which helminths respond to changes in environmental conditions. Our previous studies have demonstrated host-induced morphological modifications in S. mansoni adult worms, indicating that each host may constitute a heterogeneous environment to the parasite (Machado-Silva et al. 1994, Martinez et al. 2003, Neves et al. 2004). In the present study, we have asked whether a strain of $S$. mansoni which has been maintained in Swiss Webster mice for the past 40 years, undergoes phenotypic plasticity in A. cursor. We found that the morphological features of adult worm were similar to laboratory mice, indi-

*Corresponding author: machado@uerj.br 
cating absence of phenotypic plasticity. In conclusion, this experiment has shown that the grass mouse is a permissive host to $S$. mansoni infection.

\section{Materials and methods}

\section{Husbandry}

The study used eight mice (five-month-old) from the colony at the Laboratório de Biologia e Parasitologia de Animais Silvestres Reservatórios (Instituto Oswaldo Cruz, Brasil). Experimental mice were housed singly in standard polypropylene rodent cages $(40 \times 33 \mathrm{~cm})$ with stainless steel-screened covers. Animals were provided with rodent chow (Nuvilab CR1, Colombo, Paraná, Brazil) and water ad libitum. The experiments reported here comply with the current laws regarding ethical procedures with investigated animals.

\section{Parasite maintenance and mouse infection procedure}

The $S$. mansoni life cycle is maintained routinely in Biomphalaria glabrata snails and mice at the Laboratório de Malacologia (Instituto Oswaldo Cruz, Brasil) and prepared by exposing infected snails to light for $2 \mathrm{hrs}$ to induce shedding of parasites (Freire et al. 2003). Each mouse was exposed to approximately $150 \mathrm{~S}$. mansoni cercariae (BH strain, Brazil) by subcutaneous route, as previously reported (Machado e Silva et al. 1991).

\section{Worm procedures}

Conventional porto-hepatic perfusion was performed as described for laboratory mice (Freire et al. 2003) at day 63 after infection. Schistosomes were prepared for light and confocal microscopy by post-fixation in worm AFA (acetic acid, formalin, alcohol), staining in $2.5 \%$ hydrochloric carmine, dehydration in an alcoholic series, clearing in methyl salicylate with Canada balsam (1:2) and mounting in glass slides (Neves et al. 1998). Each whole-mount contained only a single worm (male or female). Seventy-four worms (49 males and 25 females) were examined microscopically (Olympus BX50, USA) to assess morphometry, using computer image analysis (Image Pro Plus-Media Cybernetics, USA) coupled to a Sony camera $(640 \times 480$ pixels, RGB $)$ using bright-field microscopy (Olympus BX50, USA) (Neves et al. 1998).

We studied tegument thickness, area of the oral and ventral sucker, and distance between them; perimeter, area, major

Table I. Light microscopy observations on the biometry of the tegument, suckers and reproductive system of Schistosoma mansoni adult worms recovered from Akodon cursor, Mus musculus $S W$ and Nectomys squamipes

\begin{tabular}{|c|c|c|c|}
\hline $\begin{array}{l}\text { Morphometric } \\
\text { parameters }\end{array}$ & $\begin{array}{l}\text { Akodon cursor } \\
\text { (present work) }\end{array}$ & $\begin{array}{l}\text { Mus musculus } S W \\
\text { (Martinez et al. 2003) }\end{array}$ & $\begin{array}{l}\text { Nectomys squamipes } \\
\text { (Neves et al. 2004) }\end{array}$ \\
\hline Males & $\mathrm{n}=49$ & $\mathrm{n}=60$ & $\mathrm{n}=51$ \\
\hline Tegument $(\mu \mathrm{m})$ & $10 \pm 1.9$ & - & $11 \pm 2$ \\
\hline \multicolumn{4}{|l|}{ Sucker } \\
\hline Oral area $\left(\mu \mathrm{m}^{2}\right)$ & $16057 \pm 12110$ & $19411 \pm 5799$ & $2433 \pm 7383$ \\
\hline Ventral area $\left(\mu \mathrm{m}^{2}\right)$ & $19415 \pm 15670$ & $29639 \pm 10845$ & $25721 \pm 9748$ \\
\hline Distance & $221 \pm 71$ & $159 \pm 57$ & $168 \pm 73$ \\
\hline \multicolumn{4}{|l|}{ Testicular lobes } \\
\hline Number & $8 \pm 3$ & $8 \pm 2$ & $8 \pm 2$ \\
\hline Area $\left(\mu \mathrm{m}^{2}\right)$ & $11241 \pm 4789$ & $25743 \pm 5975$ & $22734 \pm 8398$ \\
\hline Perimeter & $584 \pm 199$ & $733 \pm 127$ & $684 \pm 101$ \\
\hline Major diameter & $208 \pm 75$ & $301 \pm 51$ & $263 \pm 40$ \\
\hline Minor diameter & $53 \pm 18$ & $103 \pm 17$ & $91 \pm 14$ \\
\hline Females & $\mathrm{n}=25$ & $\mathrm{n}=49$ & $\mathrm{n}=31$ \\
\hline Tegument thickness & $4 \pm 0.8$ & - & $2.5 \pm 0.8$ \\
\hline \multicolumn{4}{|l|}{ Sucker } \\
\hline Oral area $\left(\mu \mathrm{m}^{2}\right)$ & $1817 \pm 584$ & $2078 \pm 658$ & $2024 \pm 692$ \\
\hline Ventral area $\left(\mu \mathrm{m}^{2}\right)$ & $1817 \pm 584$ & $2205 \pm 784$ & $1606 \pm 741$ \\
\hline Distance & $115 \pm 26$ & $144 \pm 31$ & $132 \pm 34$ \\
\hline \multicolumn{4}{|l|}{ Uterine eggs } \\
\hline Number & 1 & 1 & 1 \\
\hline Area $\left(\mu \mathrm{m}^{2}\right)$ & $2486 \pm 742$ & $2730 \pm 625$ & $2663 \pm 471$ \\
\hline Perimeter & $96 \pm 7$ & $245 \pm 27$ & $244 \pm 25$ \\
\hline Major diameter & $101 \pm 7$ & $95 \pm 8$ & $97 \pm 9$ \\
\hline Minor diameter & $38 \pm 11$ & $35 \pm 6$ & $33 \pm 3$ \\
\hline \multicolumn{4}{|l|}{ Ovary } \\
\hline Area $\left(\mu \mathrm{m}^{2}\right)$ & $21907 \pm 5631$ & - & - \\
\hline Perimeter & $330 \pm 62$ & - & - \\
\hline Major diameter & $770 \pm 130$ & - & $364 \pm 89$ \\
\hline \multirow{2}{*}{ Minor diameter } & $73 \pm 15$ & - & $132 \pm 27$ \\
\hline & & \multicolumn{2}{|c|}{$\begin{array}{r}\text { Brought to you by | Fundação Oswaldo Cruz FIOCRUZ } \\
\text { Authenticated } \\
\text { Download Date | 10/19/17 6:43 PM }\end{array}$} \\
\hline
\end{tabular}



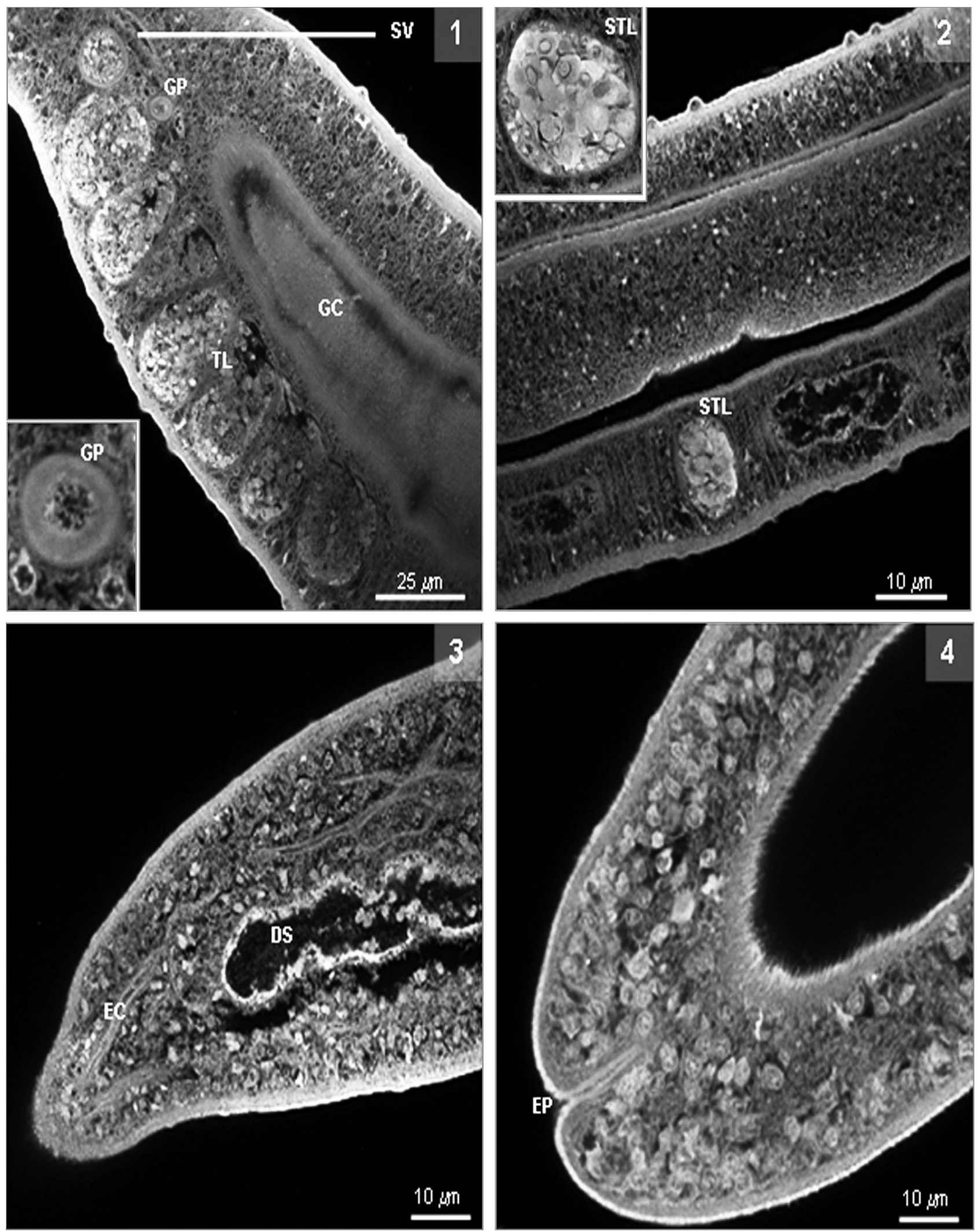

Figs 1-4. Confocal laser scanning microscopy images of the male Schistosoma mansoni stained with hydrochloric carmine. 1. Testicular lobes (TL), seminal vesicle (SV), gynaecophoric canal (GC) and genital pore (GP). 2. Supernumerary testicular lobe (STL). 3. Digestive system (DS), excretory canals ( EC). 4. Excretory pore ( EP) 

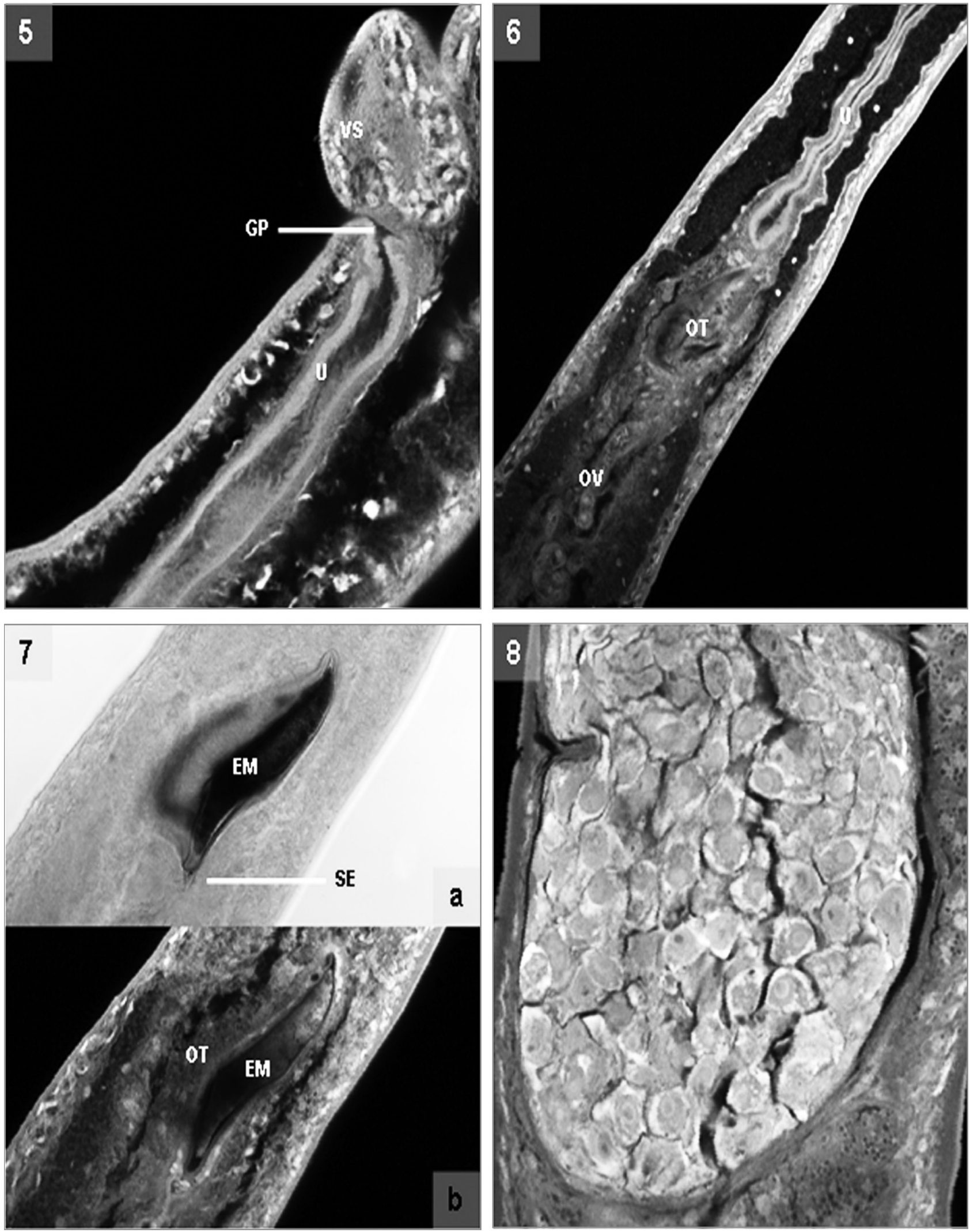

Figs 5-8. Confocal laser scanning microscopy images $(5,6,7 \mathrm{~b}, 8)$ and light microscopy (7a) ot the female Schistosoma mansoni stained with hydrochloric carmine. 5. Ventral sucker( VS), genital pore (GP) and uterus( U). 6. Uterus (U), ootype (OT) and oviduct (OV). 7. Ootype (OT) displaying a developing embryo (EM) and spine egg (SE). 8. ovary $(\mathrm{O})$ 
and minor diameter, and number of testicular lobes, uterine egg and ovary. All measurements are in micrometers unless another one has been indicated. The dimension of organs represents arithmetic mean and standard deviation (Neves et al. 1998).

The same whole-mounts were also used for further analysis by confocal microscopy (LSM 410-ZETA, Zeiss, Germany) using a $543 \mathrm{He} / \mathrm{Ne}$ laser, with an LP 570 filter. The images were transferred from the LSM computer to Microsoft ImagerTM and Corel Draw 6.0TM for final contrast, brightness and gamma correction adjustments and then printed using a Codonics NP 1600TM printer (Machado-Silva et al. 1998). The reproductive organs (testicular lobes, supernumerary testes, seminal vesicle, ovary, oocytes, seminal receptacle, vitelline glands, ootype and uterus), tegument, digestive system and excretory system were examined (Neves et al. 2005). In males, tegument thickness measurements were always taken from the region below the second testicular lobe, whereas measurements from females were taken from the area adjacent to the ventral sucker.

\section{Results}

\section{Biometric findings}

Data are presented as mean \pm SEM. The morphometric data given in Table I indicate that measures of tegument thickness $(10 \pm 1.9 \mu \mathrm{m} ; 4 \pm 0.8 \mu \mathrm{m})$, oral sucker area $(16057 \pm$ $\left.12110 \mu \mathrm{m}^{2} ; 1817 \pm 584 \mu \mathrm{m}^{2}\right)$; ventral sucker area $(19415 \pm$ $\left.15670 \mu \mathrm{m}^{2} ; 1817 \pm 584 \mu \mathrm{m}^{2}\right)$; distance between suckers (221 $\pm 71 \mu \mathrm{m} ; 115 \pm 26 \mu \mathrm{m})$ are greater in male worms than females. The measurements of the testicular lobes were: number $(8 \pm 3)$, area $\left(11241 \pm 4789 \mu \mathrm{m}^{2}\right)$, perimeter $(584 \pm 199$ $\mu \mathrm{m})$, major diameter $(208 \pm 75 \mu \mathrm{m})$ and minor diameter (53 $\pm 18 \mu \mathrm{m})$. With regard to the female reproductive system, we analysed the number (1), area $(2486 \pm 742)$, perimeter (96 $\pm 7 \mu \mathrm{m})$, larger diameter $(101 \pm 7 \mu \mathrm{m})$ and smaller diameter $(38 \pm 11 \mu \mathrm{m})$ of uterine eggs. The biometry of the ovary of each female was: area $(21907 \pm 5631)$, perimeter $(330 \pm 62 \mu \mathrm{m})$, larger diameter $(770 \pm 130 \mu \mathrm{m})$ and smaller diameter $(73 \pm 15 \mu \mathrm{m})$.

\section{Morphological findings}

The males have testicular lobes densely packed with germinative cells in different stages of maturation, seminal vesicle which opens ventrally through the genital pore near the anterior end of a ventral groove, the gynaecophoric canal (Fig. 1). All males showed seminal vesicle with spermatozoa (Fig. 1). Eight worms (16.3\%) presented supernumerary testicular lobes, which were isolated from the normal lobes and showed an amorphous appearance (Fig. 2). The digestive system blindly ends in the distal end (Fig. 3). Extending each side are two collecting ducts and an excretory bladder that opens to the outside through a posterior excretory pore (Figs 3, 4).
The female reproductive system was distinguished by a straight uterus extended to the genital pore located below ventral sucker (Figs 5, 6). Beyond the uterus, an ootype displaying a developing embryo with spine egg (Figs 6, 7) and a short oviduct linking the ovary to the ootype were evidenced (Fig. 6). An elongated ovary with differentiated cells was observed (Fig. 8).

\section{Discussion}

Wild rodents in nature often acquire infections by different helminth species over their lifetime. Indeed, such situation has driven both taxonomic (Gomes and Vicente 1984, Gomes et al. 1992) and epidemiological studies (D'Andrea et al. 2007). Even though $A$. cursor has not water-contact pattern like $N$. squamipes, its natural schistosomiasis infection was also reported (Rodrigues-Silva et al. 1992). For these reasons, A. cursor and $N$. squamipes have been bred under captivity conditions (Almeida et al. 1986, D’Andrea et al. 1996).

Experimental schistosome infections of laboratory animals, particularly mice, are used frequently to the understanding of the pathology and pathogenesis of infection to (Cheever et al. 2002). However, those animals do not have a role in the natural life cycle of $S$. mansoni. Our previous studies (Machado e Silva et al. 1991, Souza et al. 1992, Maldonado Jr. et al. 1994) and others (Ribeiro et al. 1998) have demonstrated that available knowledge can be learnt from wild rodents experimentally infected under laboratory conditions. In addition, the success of $S$. mansoni development in a wild rodent may provides a measure to assay its susceptibility or ability to maintain this parasite (Toledo et al. 2006). A. cursor possesses many qualities which would be highly desirable in a laboratory animal: it is capable of breeding successfully under simple conditions of management and displays good adaptation to laboratory facilities (D'Andrea et al. 1996). Further, it is susceptible to experimental schistosomiasis mansoni infection (Machado e Silva et al. 1991).

The aim of this study was further substantiate this susceptibility, which was assessed through morphological parameter of adult worms. Even though each host may constitute a heterogeneous environment to the parasite, host-induced morphological alterations were not found. It is known that phenotypic plasticity is an important means through which helminths respond to changing in environmental conditions. Hosts exert strong influence on the morphological features of both adult trematodes (Watson and Pike 1993) and Fasciola hepatica eggs (Valero et al. 2009). Data accumulated in recent years demonstrate that flatworms infecting hosts which are not their natural one undergo strong morphological changes (Mouhaid et al. 1997). For instance, schistosomes live in both wild rodents (Rey 1993) and laboratory-infected mice (Cheever et al. 2002). In such variable environments there are different ways to maximize fitness. An example of this are the schistosomes recovered from $N$. squamipes that show morBrought to you by | Fundação Oswaldo Cruz FIOCRUZ Authenticated 
phological variations in comparison with specimens from laboratory mice (Martinez et al. 2003, Neves et al. 2004). In addition, the number of testicular lobes enhances whether the parasite is derived from $N$. squamipes and grown up in SW mice (Machado-Silva et al. 1994). Features like body length and distance between suckers have been described to differ in worms recovered from various rodents (Machado-Silva et al. 1994, Neves et al. 1998).

Supernumerary testes lobes is an uncommon morphological feature previously also reported in S. mansoni (Najim 1951; Machado-Silva et al. 1994, 1995; Neves et al. 1998). Our previous study showed males with rudimentary ovary and a residual oviduct posterior to the normal set of testicular lobes or fully mature oocytes in variable amounts. This seems to attest the hermaphroditic roots of this parasite (Hulstijn et al. 2006). In this study, no reproductive system abnormalities were found, contrasting to those findings reported in N. squamipes (Neves et al. 2004).

A considerable weight of evidence has been accumulated to show that the full somatic development of adult worms, characterized by large size, complete formation of reproductive organs and complete tegument maturation, is reached only in permissive hosts (mice, hamster and water-rat) (Cioli et al. 1977, Machado-Silva et al. 1997). The overall conclusion of this experiment is that $A$. cursor provides a suitable environment to the parasite because the morphological features of adult worm were similar to laboratory mice. The present data, taken together with previously reported (Machado e Silva et al. 1991) confirm that the grass mouse is a permissive host to $S$. mansoni infection. Previous work in our laboratory showed that $A$. cursor develops experimental schistosomiasis mansoni infection. It means that $A$. cursor can be termed a permissive host similar to white mice (Cioli et al. 1977).

Acknowledgement. To Dr Lygia dos Reis Corrêa for S. mansoni cercariae, Department of Malacology. To Faperj for financial support.

\section{References}

Almeida C.R., Almeida A.M., Brasil D.P., Dantas Sobrinho J., Leal M.A. 1986. The rodent Akodon arviculoides Wagner, 1842 (Cricetidae) - importance in plague foci in Brazil. Memórias do Instituto Oswaldo Cruz, 81, 409-416. DOI: 10.1590/ S0074-02761986000400008.

Cheever A.W., Lenzi J.A., Lenzi H.L., Andrade Z.A. 2002. Experimental models of Schistosoma mansoni infection. Memórias do Instituto Oswaldo Cruz, 97, 917-940. DOI: 10.1590/S00 74-02762002000700002.

Cioli D., Knopf P.M., Senft A.W. 1977. A study of Schistosoma mansoni transferred into permissive and non-permissive hosts. International Journal for Parasitology, 7, 293-297. DOI:10. 1016/0020-7519(77)90038-8.

D’Andrea P.S., Horta C., Cerqueira R., Rey L. 1996. Breeding of the water rat (Nectomys squamipes) in the laboratory. Laboratory Animals, 30, 369-376. DOI: 10.1258/002367796780739835.

D’Andrea P.S., Maroja L.S., Gentile R., Cerqueira R., Maldonado A., Rey L. 2000. The parasitism of Schistosoma mansoni (Di-
genea-Trematoda) in a naturally infected population of water rats, Nectomys squamipes (Rodentia: Cricetidae) in Brazil. Parasitology, 120, 573-582. DOI: 10.1017/S003118209900 5892.

D’Andrea P.S, Gentile R., Maroja L.S., Fernandes F.A., Coura R., Cerqueira R. 2007. Small mammal populations of an agroecosystem in the Atlantic forest domain, southeastern Brazil. Brazilian Journal of Biology, 67, 179-186. DOI: 10.1590/ S1519-69842007000100025.

Freire N., Rodrigues-Silva R., Machado-Silva J.R., Rey L. 2003. A comparative parasitologic study on Biomphalaria glabrata snail and $\mathrm{C} 3 \mathrm{H} / \mathrm{He}$ mice infected with human and murine isolates of Schistosoma mansoni derived from Sumidouro, Rio de Janeiro, Brazil. Memórias do Instituto Oswaldo Cruz, 98, 783-787. DOI: 10.1590/S0074-02762003000600013.

Gomes D.C., Vicente J.J. 1984. Helmintos parasitos de Nectomys squamipes (Brants) no município de Sumidouro, RJ. Memórias do Instituto Oswaldo Cruz, 79, 67-72. DOI: 10.1590/ S0074-02761984000100008.

Gomes D.C., Lanfredi R.M., Pinto R.M., Souza W. 1992. Description of Trichuris travassosi nov. sp. (Nematoda: Trichurinae) from a brazilian rodent, by light and scanning electron microscopy. Memórias do Instituto Oswaldo Cruz, 87, 1-10. DOI: 10.1590/S0074-02761992000500004.

Gomes D.C., Cruz R.P., Vicente J.J., Pinto R.M. 2003. Nematode parasites of marsupials and small rodents from the brazilian Atlantic forest in the state of Rio de Janeiro, Brazil. Revista Brasileira de Zoologia, 20, 699-707. DOI: 10.1590/S010181752003000400024.

Hulstijn M., Barros L.A., Neves R.H., Moura E.G., Gomes D.C., Machado-Silva J.R. 2006. Hermaphrodites and supernumerary testicular lobes in Schistosoma mansoni (Trematoda: Schistosomatidae) analyzed by brightfield and confocal microscopy. Journal of Parasitology, 92, 496-500. DOI: 10. 1645/GE-3552.1.

Lenzi J.A., Mota E.M., Pelajo-Machado M., Paiva R.A., Lenzi H.L. 1995. Calomys callosus: an alternative model to study fibrosis in schistosomiasis mansoni. The pathology of the acute phase. Memórias do Instituto Oswaldo Cruz, 90, 311-318. DOI: 10.1590/S0074-02761995000200034.

Machado e Silva J.R., Oliveira R.M.F., Rodrigues-Silva R., Maldonado Jr. A., Rey L. 1991. Roedores silvestres como modelos experimentais da esquistossomose mansônica: Akodon arviculoides (Rodentia: Cricetidae). Revista do Instituto de Medicina Tropical de São Paulo, 33, 257-261. DOI: 10.1590/ S0036-46651991000400003.

Machado-Silva J.R., Galvão C., Presgrave O.A.F., Rey L., Gomes D.C. 1994. Host-induced morphological changes of Schistosoma mansoni Sambon, 1907 male worms. Memórias do Instituto Oswaldo Cruz, 89, 411-414. DOI: 10.1590/S007402761994000300021.

Machado-Silva J.R., Galvão C., Oliveira R.M., Presgrave O.A., Gomes D.C. 1995. Schistosoma mansoni Sambon, 1907: comparative morphological studies of some brazilian strains. Revista do Instituto de Medicina Tropical de São Paulo, 37, 441-447. DOI: 10.1590/S0036-46651995000500010.

Machado-Silva J.R., Lanfredi R.M., Gomes D.C. 1997. Morphological study of adult male worms of Schistosoma mansoni by scanning electron microscopy. Memórias do Instituto Oswaldo Cruz, 92, 647-653. DOI: 10.1590/S0074-02761997 000500016.

Machado-Silva J.R., Pelajo-Machado M., Lenzi H.L., Gomes D.C. 1998. Morphological study of adult male worms of Schistosoma mansoni Sambon, 1907 by confocal laser scanning microscopy. Memórias do Instituto Oswaldo Cruz, 93, 303-307. DOI: 10.1590/S0074-02761998000700060.

Brought to you by | Fundação Oswaldo Cruz FIOCRUZ 
Maldonado Jr. A., Machado-Silva J.R., Rodrigues-Silva R., Lenzi H.L., Rey L. 1994. Evaluation of the resistance to Schistosoma mansoni infection in Nectomys squamipes (Rodentia: Cricetidae) a natural host of infection in Brazil. Revista do Instituto de Medicina Tropical de São Paulo, 36, 193-198. DOI: 10.1590/S0036-46651994000300001.

Maldonado Jr. A., Gentile R., Fernandes-Moraes C.C., D’Andrea P.S., Lanfredi R.M., Rey L. 2006. Helminth communities of Nectomys squamipes naturally infected by the exotic trematode Schistosoma mansoni in southeastern Brazil. Journal of Helminthology, 80, 369-375. DOI: 10.1017/JOH 2006366.

Martinez E.M., Neves R.H., Oliveira R.M.F., Machado-Silva J.R., Rey L. 2003. Características biológicas e morfológicas de cepas brasileiras de Schistosoma mansoni em Mus musculus. Revista da Sociedade Brasileira de Medicina Tropical, 36, 557-564. DOI: 10.1590/S0037-86822003000500003.

Mouhaid G., Casanova J.C., Moné H. 1997. Plasticidad fenotípica y determinacion sistemática de parásitos: el caso de Echinoparyphium elegans. Acta Parasitologica Portuguesa, 4, 127.

Najim A.T. 1951. A male Schistosoma mansoni with two sets of testes. Journal of Parasitology, 37, 545-546. DOI: 10.2307/ 3273345 .

Neves R.H., Costa-Silva M., Martinez E.M., Branquinho T.B., Oliveira R.M.F., Lenzi H.L., Gomes D.C., Machado-Silva J.R. 2004. Phenotypic plasticity in adult worms of Schistosoma mansoni (Trematoda: Schistosomatidae) evidenced by brightfield and confocal laser scanning microscopies. Memórias do Instituto Oswaldo Cruz, 99, 131-136. DOI: 10.1590/S007402762004000200003.

Neves R.H., Lamare C.B., Machado-Silva J.R., Carvalho J.J., Branquinho T.B., Lenzi H.L., Hulstijn M., Gomes D.C. 2005. A new description of the reproductive system of Schistosoma mansoni (Trematoda: Schistosomatidae) analyzed by confocal laser scanning microscopy. Parasitology Research, 95, 4349. DOI: $10.1007 / \mathrm{s} 00436-004-1241-2$.

Neves R.H., Pereira M.J.S., Gomes D.C., Oliveira R.M.F., MachadoSilva J.R. 1998. Morphometric differences of adult worms from sympatric samples of Schistosoma mansoni Sambon, 1907 isolated from rodents and humans. Memórias do Instituto Oswaldo Cruz, 93, 309-312. DOI: 10.1590/S0074-0276 1998000700061.

(Accepted January 11, 2011)
Rey L. 1993. Non-human vertebrate hosts of Schistosoma mansoni and schistosomiasis transmission in Brazil. Research and Reviews in Parasitology, 53, 13-25.

Ribeiro A.C., Maldonado Jr A., D’Andrea P.S., Vieira G.O., Rey L. 1998. Susceptibility of Nectomys rattus (Pelzen, 1883) to experimental infection with Schistosoma mansoni (Sambon, 1907): a potential reservoir in Brazil. Memórias do Instituto Oswaldo Cruz, 93, 295-299. DOI: 10.1590/S0074-027619 98000700058.

Rodrigues-Silva R., Machado-Silva J.R., Faerstein N.F, Rey L. 1992. Natural infection of wild rodents by Schistosoma mansoni. Parasitological aspects. Memórias do Instituto Oswaldo Cruz, 87, 271-276. DOI: 10.1590/S0074-02761992000500051.

Souza J., Digiani M.C., Simões R., Luque J.L., Rodrigues-Silva R., Maldonado Jr. A. 2008. A new Heligmonellidae (Nematoda) from Oligoryzomys nigripes (Rodentia: Sigmodontinae) in the atlantic forest, Brazil. Journal of Parasitology, 95, 734-738. DOI: $10.1645 / \mathrm{GE}-1836.1$

Souza V.A., Rodrigues-Silva R., Maldonado Jr. A., Machado-Silva J.R., Rey L. 1992. Nectomys squamipes (Rodentia: Cricetidae) as an experimental model for schistosomiasis mansoni. Memórias do Instituto Oswaldo Cruz, 87, 277-280. DOI: 10.1590/S0074-02761992000500052.

Toledo R., Carpena I., Espert A., Sotillo J., Muñoz-Antoli C., Esteban J.G. 2006. A quantitative approach to the experimental transmission success of Echinostoma friedi (Trematoda: Echinostomatidae) in rats. Journal of Parasitology, 92, 16-20. DOI: 10.1645/GE-574R1.1.

Valero A.M., Perez-Crespo I., Periago V.M., Khoubbane M., MasComa S. 2009. Fluke egg characteristics for the diagnosis of human and animal fascioliasis by Fasciola hepatica and F. gigantica. Acta Tropica, 111, 150-159. DOI: 10.1016/j.actatropica.2009.04.005.

Watson J.J., Pike A.W. 1993. Variation in the morphology of adult Apatemon gracilis Rudolphi, 1819 (Digenea: Strigeidae) reared in different avian hosts. Systematic Parasitology, 26, 33-38. DOI: 10.1007/BF00009645. 